\title{
LA IGLESIA Y EL CONVENTO DE SAN LORENZO (VALENCIA), ANTIGUA SEDE DE LA PROVINCIA FRANCISCANA DE SAN JOSÉ DE VALENCIA, ARAGÓN Y BALEARES
}

\author{
POR
}

\author{
ALBERT FERRER ORTS \\ Universidad de Valencia \\ albert.ferrer-orts@uv.es
}

RESUMEN

El presente estudio trata sobre el antiguo templo de San Lorenzo de la ciudad de Valencia, sus vicisitudes histórico-artísticas a lo largo de ocho siglos y, también, del convento anexo que en la última centuria acogió a los franciscanos y sirvió de sede de la provincia de Valencia, Aragón y Baleares. Pues en fechas recientes ha sido clausurado y, previsiblemente, la iglesia volverá a ejercer como parroquia.

PALABRAS CLAVE: Templo de San Lorenzo; convento; franciscanos; Valencia; siglos XIII-XXI.

\section{CHURCH AND CONVENT OF SAN LORENZO (VALENCIA), FORMER SITE OF THE FRANCISCAN PROVINCE OF ST. JOSEPH TO VALENCIA, ARAGON AND BALEARICS}

\section{ABSTRACT}

This study deals with the ancient temple of San Lorenzo in the city of Valencia, its art-historical over eight centuries and also the convent annex vicissitudes in the last century welcomed the Franciscans and served as headquarters Valencia, Aragon and the Balearic Islands. As recently it has been closed and it is expected to return to practice church as a parish.

KEY WORDS: Temple of San Lorenzo; convent; franciscans; Valencia; XIIIth-XxIth centuries.

$\begin{array}{ll}\text { Recibido/Received } & 03-12-2013 \\ \text { Aceptado/Accepted } & 15-10-2014\end{array}$

Poco después de haberse celebrado el centenario de la apertura del convento franciscano de San Lorenzo Mártir de Valencia, el 31 de enero de 2008, este ha sido recientemente clausurado y trasladada su comunidad a diversos cenobios de la Orden. ${ }^{1}$ La que en su día fue una de las primeras iglesias de la ciudad, asolada la primitiva mezquita tras la conquista de Jaime I el Conquistador, su devenir a lo largo de la historia no ha estado exento de avances y retrocesos en cuanto a su uso, particularmente desde el siglo XIX hasta la fecha, en la que, previsiblemente, volverá a desempeñarse como parroquia de la diócesis o como templo de una orden contemplativa.

\footnotetext{
1 Según refiere la resolución del Capítulo de 2013, véase http:// www.fmval.org/ (consultada el 20-11-2013).
}

\section{ANTECEDENTES HISTÓRICOS}

Situada intramuros de la ciudad del Turia, los primeros testimonios que hablan de su emplazamiento se remontan al bajo Imperio romano, circunstancia confirmada por el hallazgo de una inscripción honorífica sobre mármol de Buixcarró en un pedestal con base y cornisa, localizada en 1853 a la entrada de la plaza de San Lorenzo (ante lo que fue el palacio de la Inquisición). Se trata de una dedicatoria de los ciudadanos de Valentia al emperador Claudio II el Gótico (año 269). ${ }^{2}$

Sin embargo, independientemente de este hecho puntual, cabe referir que no tenemos constancia de otros

2 Corell Vicent, J. 1997. Inscripcions romanes de Valentia i el seu territori: 88-89 València: Nau Llibres; obra reeditada en 2009. Inscripcions romanes de Valentia i el seu territori, amb la col-laboració de Xavier Gómez Font: 76-77 València: Col-lecció Fonts Històriques Valencianes, Universitat de València. 
vestigios que, producto de la casualidad o de excavaciones arqueológicas, puedan enlazar fehacientemente este pasado romano con el posterior asentamiento cristiano en la alta Edad Media. Por consiguiente, y como consecuencia de esta merma de información de campo a pesar de la progresiva evolución urbana del lugar, las fuentes sobre las que basarse son fundamentalmente de naturaleza documental y literaria.

Cuando las tropas de Jaime I tomaron la ciudad a los musulmanes después de casi seis siglos de predominio islámico, Valencia (Balansiya) mostraba el trazado propio de esta civilización, amurallado, y, por tanto, condicionante de su urbanismo intramuros. Una red urbana irregular que se extendía desde el antiguo foro romano, sobre el que se elevaba la mezquita mayor, y que solamente fue ensanchándose a medida que el perímetro de sus murallas lo hizo.

Las informaciones que sobre este período disponemos son de carácter bibliográfico, y vienen a referir que el solar que ocupa el actual templo de San Lorenzo fue una mezquita, razón por la que, cuando los cristianos ocuparon la ciudad, la convirtieron en iglesia como los casos del Salvador, San Bartolomé, San Esteban y otras más. Sin embargo, como hemos referido, no tenemos constancia de ninguna cata arqueológica o hallazgo esporádico que pueda confirmar las noticias y las sospechas transmitidas por las fuentes historiográficas. ${ }^{3}$

En 1239 aparece en el real registro Memoriarum de Domibus Valentie de anno 1239 llamada ya como iglesia de San Lorenzo (titularidad que posiblemente compartiera con San Gil), mientras que en el Llibre del Repartiment se refiere al lado de la casa de Mahomat Amançor (en el barrio de Daroca), que fue la segunda iglesia parroquial capitalina en antigüedad después de la del Salvador, quizás erigida en honor a este santo por creerse desde antiguo que fue oriundo de Valencia, mientras que en 1245 aparece relacionado con ella como uno de sus primeros rectores el sacerdote mosén Pedro Eiximenis, ${ }^{4}$ informaciones que podrían avalar la hipótesis de que fuera una mezquita antes de la conquista cristiana. Hasta un siglo más tarde, en 1373, no volvemos a encontrar noticias de la misma, época en que pudo ser renovada o ampliada su fábrica original de $1276 .^{5}$

\section{LA PARROQUIA DE SAN LORENZO}

En el siglo XV se documenta una intervención parcial en el interior de San Lorenzo, financiada por el caballero Nicolás Català de Valeriola (tal y como recuerda una lápida conmemorativa fechada el 28 de enero de 1489). ${ }^{6}$ Se trataba de una

\footnotetext{
3 Sobre el particular, Burns, R. I. 1993. El regne croat de València. València: Tres i Quatre.

4 Teixidor, J. OP. 1985. Antigüedades de Valencia, I: 367-369 Valencia: Biblioteca Valenciana, Librerías París-Valencia. Edición facsímil de la edición de Valencia: Imp. de Francisco Vives Mora. 1895. A propósito del convento e iglesia de San Lorenzo, Agulló, B. 2009. Convento de San Lorenzo, Franciscanos de Valencia. Valencia, particularmente los capítulos III al VI.

5 Teixidor, J. OP. 1985. Antigüedades de Valencia, I: 367-368. Véase también, Corbín Ferrer, J. L. 1988. Valencia histórica: entre EI Salvador y Serranos: 113-124 Valencia: Federico Doménech Ed.

6 Reproducida íntegramente por Corbín Ferrer, J. L. 1988: 114. Sobre el emplazamiento urbano de la iglesia, resulta útil la obra de Arciniega García, L. 2003. El palau dels Borja a València. València: Corts Valencianes.
}

capilla lateral bastante profunda a los pies del edificio religioso que perduró hasta 1908-1909, cuando fue casi totalmente derruida para poder levantar el convento franciscano anexo, mientras los conventuales se hallaban domiciliados provisionalmente en la calle de Samaniego. Construcción de tipología gótica con bóvedas de crucería, seguramente, que pudo servir de capilla privada de esta familia nobiliaria domiciliada en la calle de Nules de la capital.

\section{ILUSTRACIÓN I}

Lápida de Nicolás Català de Valeriola, siglo xv. Foto JBM

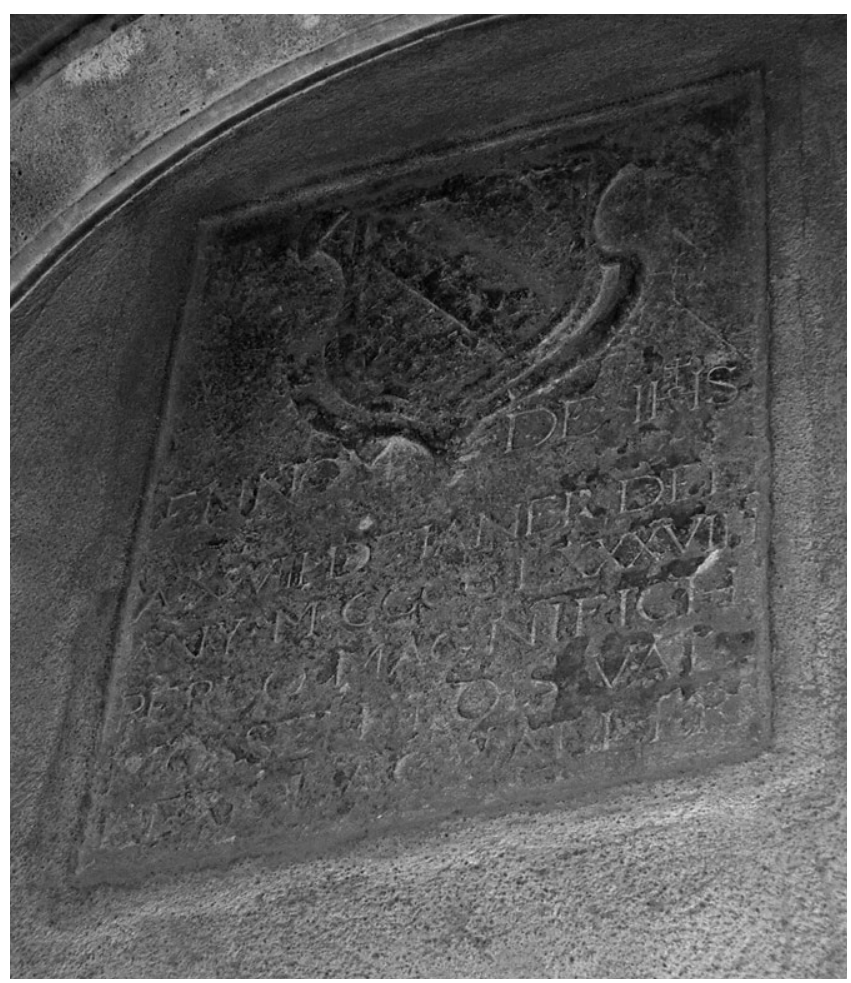

En 1550, los jurados de Valencia concedieron a la citada parroquia la posibilidad de tomar censos en compensación por los que había perdido por el ensanche del camino real a su paso por el monasterio de San Miguel de los Reyes. ${ }^{7}$ Mientras que en las postrimerías del siglo XVI y el inicio del siglo XVII se documentan entre sus paramentos las residencias de mujeres emparedadas. ${ }^{8}$

Durante el siglo XVII, las informaciones relativas a la iglesia son cuantitativamente numerosas y cualitativamente importantes, por cuanto aluden a la incidencia de la peste de 1648 entre los feligreses de la parroquia laurenciana, contabilizándose 228 víctimas, siendo rector y vicario de la misma Bernardo Salafranca y Domingo Báguena, respectivamente. ${ }^{9}$ En 1656 consta que el maestro de obras Jerónimo Bexet cobró

7 Arciniega García, L. 2001. El monasterio de San Miguel de los Reyes: 1, 128. Valencia: Biblioteca Valenciana.

8 Orellana, M. A. de. 1980. Tratado histórico-apologético de las mugeres emparedadas: 125. Valencia: Biblioteca Valenciana, Librerías París-Valencia. Edición facsímil de la edición de Valencia: Imp. de la Casa de Beneficencia. 1887.

9 Gavaldà, F. OP. 1979. Memoria de los sucesos particulares de Valencia, y su Reino en los años mil seiscientos quarenta y siete y quarenta y ocho, tiempo de peste: sp Valencia. Librerías París-Valencia. Edición facsímil de la edición de Valencia: Imp. de Joseph de Orga. 1804. 
del rector de San Lorenzo por una casa cercana al cementerio parroquial, ${ }^{10}$ mientras que en 1662 se hizo inventario de la sacristía de la capilla de la Virgen, ${ }^{11}$ se contratan con el escultor Vicente Mir dos pilas de piedra para la sacristía y se le liquidan al pintor José Tora emolumentos por ejecutar candelabros y escaleras en el monumento. ${ }^{12}$ Sin embargo, los documentos que con toda claridad nos informan de las importantes transformaciones edilicias del templo se fechan en el último cuarto de la centuria, ya que en 1682 el gremio de zapateros, que tenía en San Lorenzo su capilla corporativa dedicada a San Crispín y San Crispiniano, acordó reformarla con el maestro de obras Tomás Alepuz. ${ }^{13}$ Pero, sobre todo, es de vital importancia la decisión de la junta de fábrica de proceder al derribo del antiguo templo y la construcción de una nueva iglesia, basada en las trazas de Gaspar Díez, por parte del maestro de obras Agustín Maiques (artífice en esas fechas de la iglesia parroquial de Xirivella y documentado profesionalmente en tierras castellonenses). ${ }^{14}$ Se trató de la conversión del espacio medieval en otro más escenográfico, ampuloso y técnicamente acorde a su tiempo -aunque sujeto al ya preexistente, por cuanto la cimentación y los contrafuertes medievales fueron reaprovechados. El edificio resultante, incluidas las dos portadas obra del arquitecto Pedro Angost y del cantero Bernardo Pons, es el que podemos observar grosso modo en la actualidad, especialmente por lo que se refiere a su decoración ${ }^{15}$ y a la torre campanario, añadida en la primera mitad del siglo XVIII.

Del mismo modo que se renovó su fábrica, tenía que ser dotada de obras de arte muebles que fueran al unísono con la decoración barroca; así pues, en 1683 se acordó la erección de un nuevo retablo diseñado por Tomás Vergara y ejecutado por del reputado escultor Leonardo Julio Capuz. ${ }^{16}$ Se trata de uno de los escasos conjuntos salomónicos originales que todavía se conservan en la diócesis de Valencia, a pesar de la pérdida de piezas escultóricas desde la pasada Guerra Civil que, además, sirvió de modelo para que el mismo artífice construyera el de la parroquial de San Miguel Arcángel de Burjassot. Cabe indicar que el día que se colocó la escultura del santo titular, en 1684, se instauró una procesión solemne los 10 de agosto, día de su festividad, que recorría las parroquias vecinas y la catedral. ${ }^{17}$

10 Archivo de Protocolos del Patriarca de Valencia (APPV), Protocolos de Cosme Puig, no 17.542 (agradecemos la información a María José López Azorín). Para las obras acontecidas durante el siglo XVII en esta iglesia, consúltese el estudio de Pingarrón, F. 1998. Arquitectura religiosa del siglo XVII en la ciudad de Valencia: 237-244. Valencia: Col-lecció Estudis, 12, Ajuntament de València.

11 APPV, Protocolos de Cosme Puig, no 17.547. Agradecemos la información a María José López Azorín (Apéndice documental, doc. № 1).

12 APPV, Protocolos de Mateo Bonastre, $\mathrm{n}$ - 11.476. Agradecemos la información a María José López Azorín.

13 Archivo del Reino de Valencia, Protocolos de José Fuentes, no 959. Agradecemos la información a María José López Azorín.

${ }_{14}$ Gil Saura, Y. 2004. Arquitectura barroca en Castellón. Castellón: Diputación Provincial de Castellón.

15 Pingarrón, F. 1998: 238-243.

16 Pingarrón, F. 1998: 243-244. Sobre Capuz, continúa siendo imprescindible la consulta de Igual Úbeda, A. 1953. Leonardo Julio Capuz (escultor valenciano del siglo XVIII). Valencia: Institución Alfonso el Magnánimo, Servicio de Estudios Artísticos.

17 Sobre este aspecto, véase Benito Goerlich, D.; Serra Desfilis, A. 1995. El Palau de les Corts, antiga casa dels Borja: 103-113 València: Consell Valencià de Cultura.

\section{ILUSTRACIÓN II}

Portada de la iglesia recayente a la plaza de San Lorenzo. Foto JBM

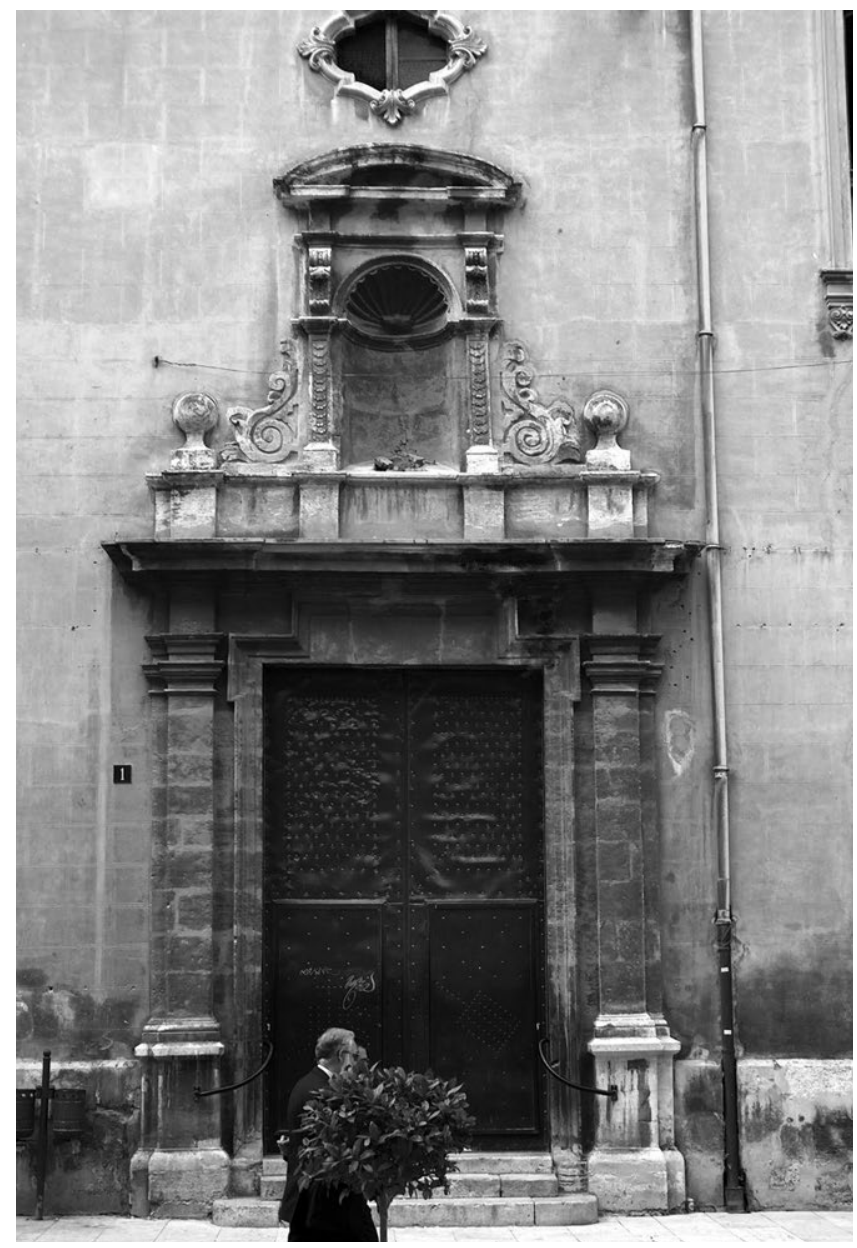

Ya en la siguiente centuria, concretamente en 1708, tenemos constancia de que mosén Vicente Pérez Castiel Artigues, archivero de la parroquia e hijo del reputado arquitecto Juan Pérez Castiel, recibió poderes de su padre por hallarse exiliado en el reino de Castilla y así poder encargarse de sus asuntos. Años en los que, muy posiblemente, Juan Bautista Pérez Castiel Artigues -otro de los hijos del arquitecto aragonés, perito además en cuestiones de arquitectura- coincidió como beneficiado de San Lorenzo. ${ }^{18}$ Con todo, el linaje de este destacado autor turolense continuó teniendo una estrecha relación con la antigua parroquia valenciana, ya que, al no poseer torre de campanas dicho edificio por haberse derruido la fábrica gótica en 1680 por el maestro de obras Lorenzo Cassanya, en 1743 se capitula con el arquitecto José Mínguez -tradicionalmente considerado sobrino de Pérez Castiel, pero muy probablemente su hijo natural- la elevación de un campanario en el lado de la Epístola de la capilla mayor (justamente en la parte contraria en la que estuvo la torre medieval y donde, en principio, se intentará levantar de nuevo). Una de las construcciones de ladrillo más esbeltas y mejor ejecutadas en dicho período. ${ }^{19}$ Tiempos en los

18 López Azorín, M. J. 1993. “El testamento de Juan Pérez Castiel y otras noticias biográficas". Archivo de Arte Valenciano LXXIV: 75-80.

19 APPV, Protocolos de José Portillo, no 4.491, ff. 43 v.-53 v. y 91 r.-92 v. Sobre el particular, véanse las contribuciones de Juan Vidal, 
que sospechamos se pintaron al fresco cuatro óvalos con escenas biográficas del santo titular por manos anónimas, las cuales se ubicaron en el centro de cada uno de los tramos de la bóveda, aunque la historiografía los considera casi unánimemente obra de Antonio Palomino o, más factiblemente, de alguno de sus discípulos contemporáneos.

\section{ILUSTRACIÓN III}

Fachada del templo y torre de San Lorenzo. Foto JBM

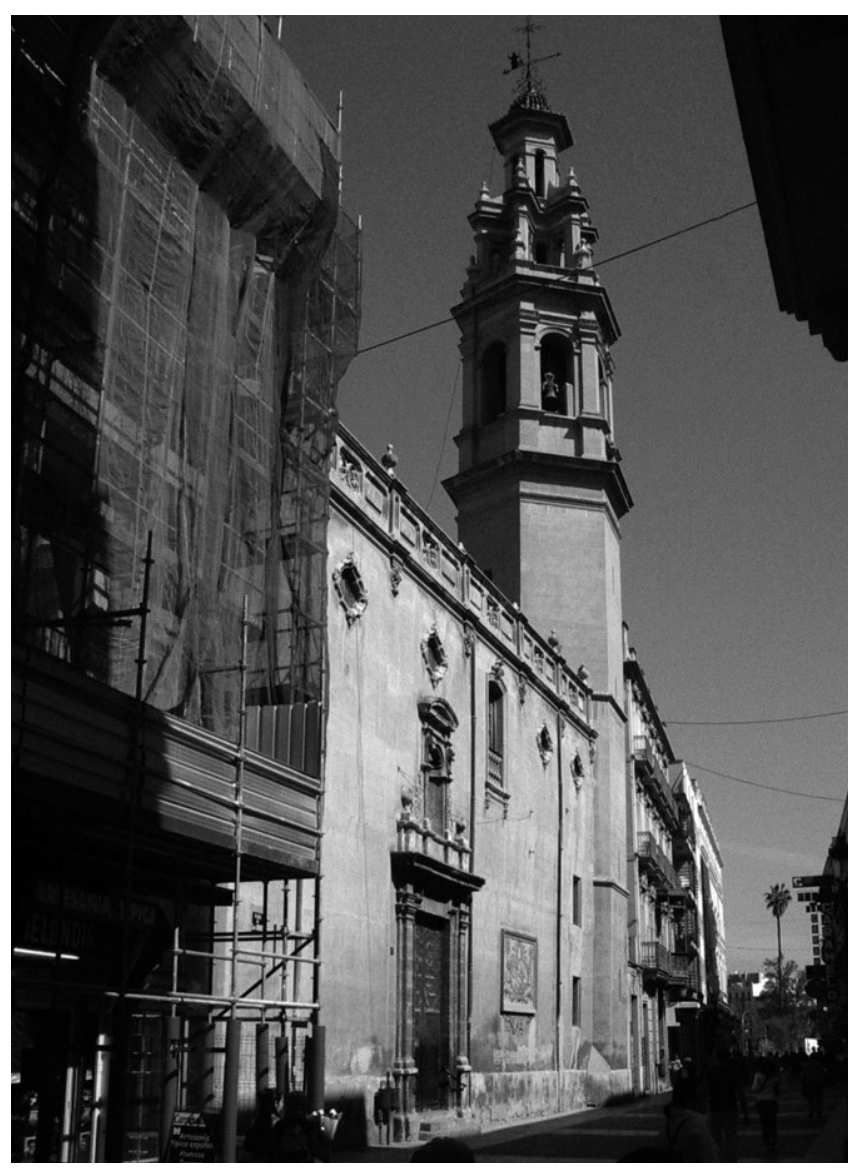

En las postrimerías del siglo XVIII, concretamente en 1770, tres de los arquitectos académicos más destacados del período: Antonio Gilabert, Vicente Gascó y Juan Bautista Mínguez, una vez personados en el templo, presentaron un informe a la Real Academia de San Carlos de Valencia evaluando unas grietas detectadas en las arcadas y las bóvedas del edificio, ${ }^{20}$ circunstancia que nos hace pensar que entonces comenzaron a aparecer los primeros problemas estructurales en el mismo, los cuales se agravaron cuando el 5 de marzo de 1822 un seísmo hizo oscilar levemente el campanario provocando algunas fisuras en su caña.

F. 2000. Los campanarios de José Mínguez (Valencia 1700-1750). Valencia: Ediciones Generales de la Construcción, y González Tornel, P. 2010. “José Mínguez. Un arquitecto barroco en la Valencia de la primera mitad del siglo XVIII". Goya 332: 218-219, resumen de su obra editada en el mismo año José Mínguez. Un arquitecto barroco en la Valencia del siglo XVIII, Castellón: Col·lecció Humanitats, 35, Universitat Jaume I: 94 y ss.

20 Archivo de la Real Academia de Bellas Artes de San Carlos de Valencia, Acta de 4 de marzo de 1770. Véase también, Bérchez, J. 1987. Los comienzos de la arquitectura académica en Valencia: Antonio Gilabert: 78 Valencia: Federico Doménech Ed.
En el siglo XIX es probable que la parroquia contara con una vicaría extramuros: la iglesia de San Antonio. ${ }^{21}$ En este contexto, el templo de San Lorenzo continuó prestando con normalidad sus servicios litúrgicos hasta que en 1903 le fue retirada su condición de parroquia y trasladada a la iglesia de Nuestra Señora del Pilar, a la par que sus campanas, las cuales fueron permutadas por dos pertenecientes al templo del antiguo convento dominico y que hoy todavía se conservan en la torre de San Lorenzo (Ilamadas Benito, Ana, Fulgencio -1718-y Domingo-1742).22

\section{EL CONVENTO FRANCISCANO DE SAN LORENZO}

A principios de 1908 el templo volvió a tener uso y, por decisión del arzobispo Victoriano Guisasola, fue regentado por franciscanos menores, ${ }^{23}$ quienes, a los seis meses de tomar posesión y adquirir un pequeño solar anexo que coincidía con el antiguo cementerio, iniciaron el derribo de la mayor parte de la capilla de los Valeriola, a los pies del edificio, de la sacristía y de diversas dependencias para poder construir el convento que obviamente necesitaban, así como la capilla de la Comunión en el lado del Evangelio, por lo que la iglesia resultante fue más bien claustral y no necesariamente hallenkirchen como se ha llegado a sugerir. La traza del mismo fue obra de fray Maseo Company ${ }^{24}$ y su construcción responsabilidad del maestro de obras Rafael Sancho, de Godella, quien lo remató en noviembre de $1909 ;{ }^{25}$ artífices que también intervinieron la bóveda del templo entre 1912-13 al amenazar ruina, según dictamen del arquitecto Antonio Martorell, renovándose integralmente la del presbiterio. Por lo que se procedió al desmontaje de la techumbre, se sustituyó por una nueva de menor verticalidad con

21 Madoz, P. 1982. Diccionario geográfico-estadístico-histórico de Alicante, Castellón y Valencia: II, 251 Valencia: Institución Alfonso el Magnánimo. Edición facsímil de la edición de Madrid: Tip. P. Madoz. 1845-1850.

22 Llop i Bayo, F.; Martín Noguera, X. 1998. Metodologia dels inventaris de campanes. Fitxa d'inventari de Sant Llorenç de València (28-12-1969), Fitxa d'inventari de Sant Llorenç de València (4-7-2000).

23 Sobre el franciscanismo en tierras valencianas, DDAA. 1995. Franciscanisme al País Valencià. València: Monogràfics. 22. Saó; y Agulló, B. 2009: caps. I y II. Respecto a las vicisitudes de los franciscanos en Valencia desde finales del siglo XIX hasta su definitiva residencia en el convento e iglesia de San Lorenzo, Archivo del Convento de San Lorenzo de Valencia (ACSLV), Ms. DDAA. Datos para la Crónica del Convento-Residencia de San Lorenzo Mártir de Valencia: 1-90, así como Agulló, B. 1965. Seráfica Provincia de San José de Valencia. Valencia, y Agulló, B. 2009: caps. II-VI.

24 Agulló, B.; Prado, E. de. 2002. Fray Maseo Company Alfonso "arquitecto". Valencia; autor a quien también le ha dedicado su atención Cebrián i Molina, J. L. 1990. "La catedral de La Marina: una gran església neogòtica a Benissa", Actes del III Congrés d'Estudis de La Marina Alta: 367-379 Dénia: Institut d'Estudis Comarcals de La Matina Alta, Institut de Cultura Juan Gil-Albert, Escola-taller Castell de Dénia, y del mismo autor. 2002. "L'església neogótica de Benissa", Festes Puríssima Xiqueta: sp.

25 ACSLV, Ms. Llorens Moltó, F. OFM. “Crónica del Convento de San Lorenzo (años 1909-1940). Primera parte": 101 y ss., en DDAA, Datos para la Crónica del Convento-Residencia de San Lorenzo Mártir de Valencia. El convento fue declarado residencia oficial de los Ministros Provinciales el 9 de mayo de 1910 y elevada al grado de guardianía el 16 de noviembre de 1911 (DDAA. 1928. "Bodas de Oro de la restauración de la Seráfica Provincia de Valencia: 1878-1928". La Acción Antoniana, número extraordinario: 50). 
tirantes de hierro y teja catalana, respetando la bóveda tabicada seiscentista original, lo que obligó a su redecoración y, al mismo tiempo, a la colocación de un nuevo pavimento. ${ }^{26}$

\section{ILUSTRACIÓN IV \\ Acceso al primitivo convento por la calle de Franciscanos. Foto JBM}

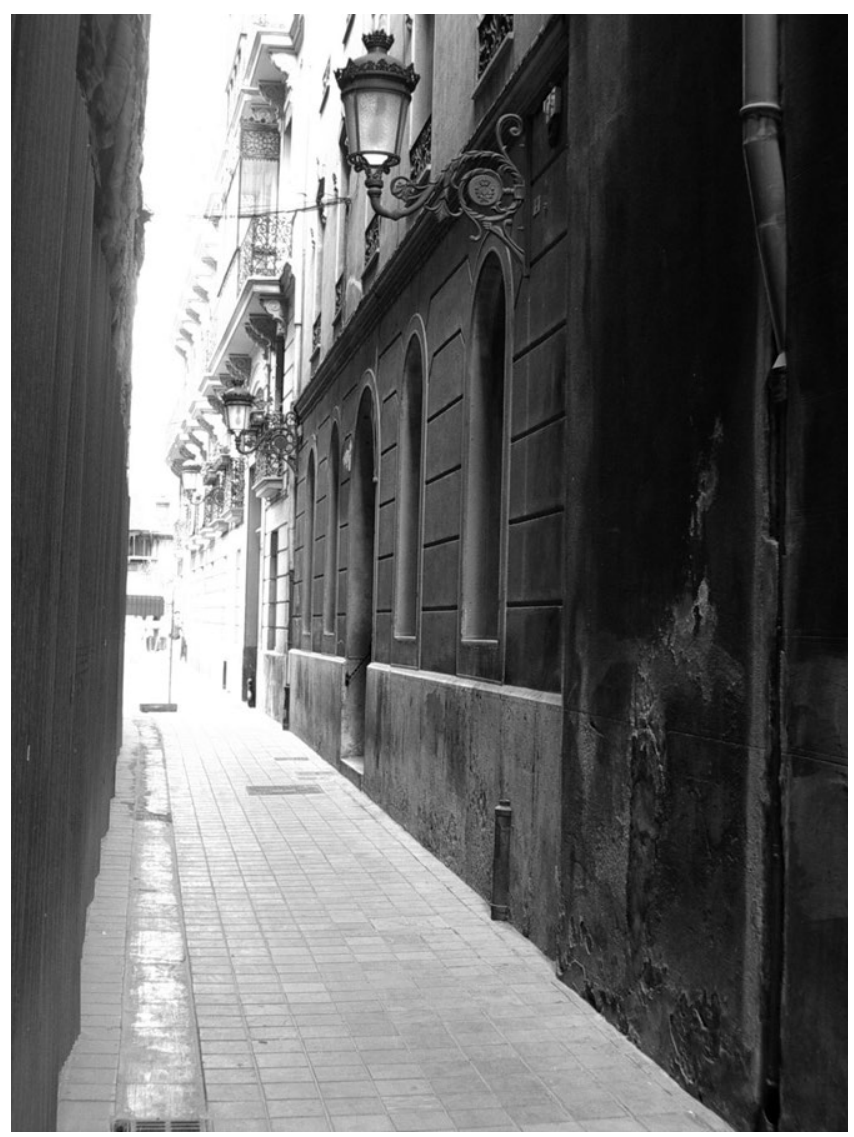

Años más tarde, en 1916 -seguramente por la necesidad de adecuar la fachada que recae en la plaza de San Lorenzo $y$, al mismo tiempo, confronta con el antiguo palacio del duque de Gandia-, la comunidad franciscana encargó al joven arquitecto Javier Goerlich Lleó un proyecto para la misma. A pesar de las advertencias del arquitecto del Ayuntamiento de Valencia Francisco Mora, se diseñó una fachada ecléctica, que no está en sintonía con las líneas estilísticas del templo y que le confiere una extraña apariencia institucional. ${ }^{27}$ En 1921 se reforzó la parte superior de las capillas de lado de la Epístola, concretamente entre el campanario y el coro alto, con vigas de hierro para poder instalar una tipografía, imprenta que comenzó a funcionar el 2 de agosto de ese mismo año. ${ }^{28}$

26 ACSLV, Papeles sueltos, “Iglesia de San Lorenzo. Su reparación” (1912-13), sf. (Apéndice documental, doc. no 3)

27 Archivo Histórico Municipal de Valencia, Fomento, Policía Urbana, 1916 (Apéndice documental, doc. no 4). Resulta interesante la descripción de la iglesia que por esas fechas realiza mosén P. Sucías Aparicio, en la Biblioteca Municipal de Valencia, Ms., Sucías 54, Justificantes a la Historia de Valencia: t. I, parte 1a: 93-94

28 ACSLV, Ms. Llorens Moltó, F. OFM. “Crónica del Convento de San Lorenzo (años 1909-1940). Primera parte": 140-141, en DDAA. Datos para la Crónica del Convento-Residencia de San Lorenzo Mártir de Valencia.
ILUSTRACIÓN V

Fachada de la plaza de San Lorenzo (detalle). Foto JBM

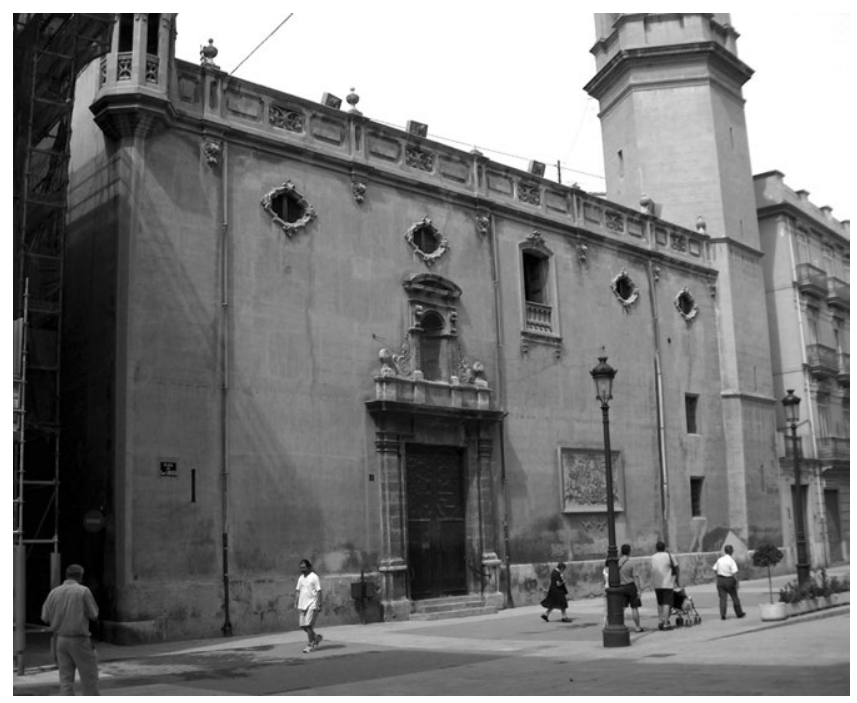

El 20 de julio de 1936 la iglesia se cierra al culto y la comunidad se dispersa. La mayor parte del archivo, ornamentos, libros... se perdieron. El edificio (iglesia y convento) se convirtió en oficinas y depósito-almacén, respectivamente. La escultura del titular en el altar mayor desapareció, como también la mesa de celebraciones (obra de Ponsoda, en 1921) y su frontal, idéntico destino al que corrieron el Salvador eucarístico del expositor (1927) del pintor Rafael Belenguer y el Viacrucis de Pascual. Los retablos laterales -la mayor parte de los cuales, excepto los de Santa Rita, la Virgen del Rosario y el Cristo de los Navegantes habían sido renovados por los escultores Pastor y Ponsoda- tuvieron el mismo destino, no así el magnífico retablo mayor (exceptuando sus imágenes exentas).

En abril de 1939 los franciscanos volvieron al convento y el 10 de junio siguiente se bendijo de nuevo el templo, certificando las pésimas condiciones en el que había quedado por su anterior uso (profuso tabicado, alteraciones en el piso, barandas destrozadas, profunda alteración de la decoración...). A partir de este mismo año y de los subsiguientes (1940-1942, principalmente), la actividad para volver a conferirle al conjunto franciscano la dignidad y adecuación necesarios fue frenética, condicionada por la gran cantidad de oficios litúrgicos que, desde la iglesia, se ofrecía diariamente a feligreses y viandantes. ${ }^{29}$ En este ambiente es donde hay que incidir en la labor de los escultores Ponsoda (quien tenía su taller muy cercano a la sede franciscana), Teruel, Lluch o Fabra, del tallista Cuesta y de los pintores Belenguer, García Cordellàs o Gabriel Badenes. ${ }^{30}$ Autores de la nueva imagen interior del templo, la cual fue completándose posteriormente de la mano de otros artistas, como por ejemplo del pintor Rafael Cardells.

\footnotetext{
29 Ibídem. 93 y ss.
}

30 ACSLV, Ms. Llorens Moltó, F. OFM. “Crónica del Convento de San Lorenzo (años 1909-1940). Segunda parte": 173 y ss., en DDAA. Datos para la Crónica del Convento-Residencia de San Lorenzo Mártir de Valencia. 


\section{ILUSTRACIÓN VI \\ Antiguo convento de franciscanos e iglesia anexa. Foto JBM}

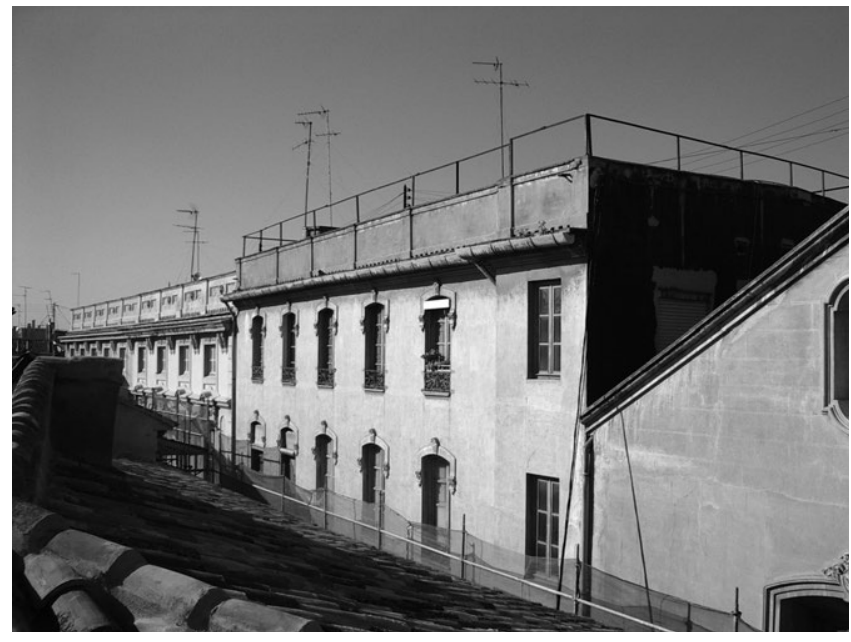

También se adquirió alguna obra ajena al medio valenciano, como la excelente imagen del titular que, alojada des del 7 de agosto de 1940 en el retablo mayor, fue donada por las clarisas del convento de San Francisco de Calatayud. En origen, un presente del cardenal Pedro de Luna, futuro Benedicto XIII, al convento de San Lorenzo, en el que residían como monjas sus hermanas Urraca y Catalina. ${ }^{31}$

\section{EL INTERIOR DE LA IGLESIA}

Nos encontramos ante el típico templo urbano que se asienta sobre construcciones precedentes, lo cual ha condicionado sobremanera sus modestas dimensiones y forma. Así debió de ser desde que, tras la conquista cristiana de la ciudad, se consagraran sus mezquitas y, más adelante, se destruyeran para erigir nuevos templos de acuerdo al dogma recién instaurado. Edificios que adoptaron una tipología conocida como de reconquista, catalana o mediterránea por su austeridad a través de amplios arcos diafragmas ligeramente apuntados de piedra o ladrillo, así como la tabiquería, tejado a dos vertientes, puerta lateral, capillas entre los contrafuertes...

La iglesia de San Lorenzo obedece a este modelo, circunstancia que se entrevé en su planta, especialmente en los contrafuertes de la nave principal, en el acceso lateral y en sus dimensiones. Estructura que, según parece, sufrió cambios cualitativos exceptuando la capilla nobiliaria, espacio que daba la apariencia de ser casi independiente del propio templo atendiendo a su ambiciosa planificación espacial (y que en la actualidad se reduce al tránsito entre la nave principal y la capilla de la Comunión, un tramo de esta última y la correspondiente a la Virgen del Castillo).

La torre campanario se hallaba en aquel tiempo en la cabecera, como se ha dicho, en el lado del Evangelio de la iglesia y, parece, por los dibujos de Anton van den Wijngaerde, que su caña era pétrea con abertura en el

31 ACSLV, Ms. Llorens Moltó, F. OFM. “Crónica del Convento de San Lorenzo (años 1909-1940). Primera parte": 127-128, en DDAA. Datos para la Crónica del Convento-Residencia de San Lorenzo Mártir de Valencia. cuerpo superior para habilitar las campanas. Por su tipología, sospechamos que pudo ser edificada en el siglo xIV o los inicios de la siguiente centuria.

En el último cuarto del siglo XVII es cuando se plantea la remodelación más importante de la construcción medieval, ya que se echa abajo el edificio hasta la línea de impostas -conservándose los contrafuertes-, se eleva su altura con la masiva utilización del ladrillo, se abre otro acceso a los pies del mismo (que junto con el primitivo son dotados de llamativas portadas de piedra inspiradas en el cercano templo de San Bartolomé) y se cubre con una bóveda tabicada ligeramente rebajada con lunetos que acogen las ventanas cenitales. Parece ser que en aquel tiempo el campanario amenazó ruina, lo que obligó a derruirlo, quedando huérfano de él, pues no volvió a edificarse hasta el siglo XVIII. En este tiempo es cuando se decidió decorar su interior con un gran retablo de madera dorada de estilo salomónico que se ajusta ejemplarmente a las directrices constructivas y ornamentales vigentes en el reino de Valencia, a pesar de estar hoy desprovisto de sus esculturas de bulto originales.

\section{ILUSTRACIÓN VII}

Altar y retablo mayor del templo. Foto JDA

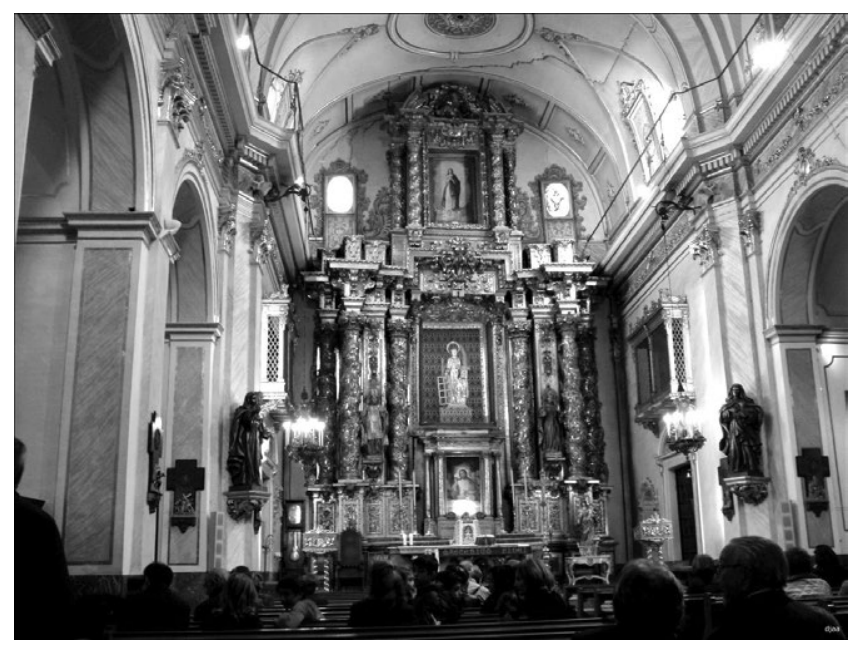

No obstante, esta importante reforma no dejó completamente satisfechos a los feligreses y la junta de fábrica parroquial, ya que en el ecuador del siglo XVIII se decidió construir una esbelta torre hexagonal de mazonería y ladrillo fundamentalmente, la cual cambió de ubicación al situarse frente el emplazamiento de la anterior y formando ahora parte de la fachada principal. Igualmente, se aprovechó la ocasión para fabricar un nuevo órgano a cargo de Martín Usurralde y Matías Salanova, ${ }^{32}$ lo que obligó a remodelar otros espacios que no se contemplaron meses antes, cuando se capituló la obra del campanario. Por este tiempo, intuimos que se ejecutaron los cuatro óvalos al fresco de la bóveda, de factura anónima, con sendas escenas alusivas al martirio del santo titular, programa muy interesante que pensamos fue realizado en la segunda mitad de la centuria.

32 APPV, Protocolos de José Portillo, no 4.491, ff. 87 v.-90 v. (Apéndice documental, doc. $\mathrm{n}$ - 2). Sobre ambos organistas ha tratado en profundidad Pingarrón, F. 1984. "La factoría de órganos Salanova-Usurralde-Grañena. 1719-1728-1738". Cabanilles 10-11 (monográficos). 
Quizás, durante el siglo XIX pudo haber alguna intervención de mantenimiento que no afectaría de manera sustancial al conjunto. ${ }^{33}$ Sin embargo, desde el inicio del siglo $\mathrm{xx}$ el templo fue profundamente alterado por diversas razones ya tratadas: la primera fue la decisión de destruir la mayor parte de la capilla de los Català de Valeriola por tal de poder construir el convento en el pequeño solar anexo. Hecho que condicionó además la construcción de la capilla de la Comunión, levantada sobre pilares achaflanados y cubierta mediante tres bóvedas vaídas ligeramente peraltadas (decoradas a través de ocho registros) y una falsa cúpula en el altar. Como resultado, las capillas del lado del Evangelio fueron eliminadas y el templo se convirtió en parcialmente claustral. La segunda fue la necesidad de cambiar la cubierta y rehacer el tramo de la cabecera, lo que obligó a redecorar el templo y, por último, la construcción de un coro elevado a los pies para que los religiosos franciscanos pudieran escuchar misa accediendo directamente desde el vecino convento.

Más adelante, como se ha referido, se registraron obras en la fachada que recae en la plaza de San Lorenzo, transformación esta postrera que le confirió una peculiar apariencia hasta nuestros días. Y, poco después, también se intervino en el pasadizo que une el coro con la torre-que discurre por encima de las capillas de la Epístola- por medio del reforzamiento del solado con vigas de hierro.

Finalmente, por efecto de la Guerra Civil, los franciscanos fueron expropiados y el conjunto pasó a la República, que habilitó ambas dependencias como oficinas (convento) y almacén (iglesia). El resultado fue devastador por las numerosas transformaciones que el mismo padeció y que provocó que la mayor parte de sus obras muebles desaparecieran. En la postguerra el templo volvió a recuperar parte del lustre que lo caracterizó históricamente, ${ }^{34}$ a pesar de que el paso del tiempo y la necesidad de reforzarlo estructuralmente hacen pensar que pueda ser objeto de una profunda intervención global futura. ${ }^{35}$

\section{BiBLIOGRAFÍA}

Arciniega García, L. 2001. El monasterio de San Miguel de los Reyes. 1. Valencia: Biblioteca Valenciana.

Arciniega García, L. 2003. El palau dels Borja a València. València: Corts Valencianes.

Agulló, B. OFM. 1965. Seráfica Provincia de San José de Valencia. Valencia

33 Martínez Aloy, J. 1920-27. "Provincia de Valencia", en Geografía general del Reino de Valencia: 2, 820, en F. Carreras y Candi (dir.) Barcelona: Alberto Martín, refiere que el 5 de marzo de 1822 y a consecuencia de un terremoto la torre osciló, agrietando la bóveda de la iglesia, la cual amenazó ruina "( ) que los piadosos feligreses han venido conjurando hasta nuestros días, mediante obras de consideración y laudables sacrificios".

${ }_{34}$ ACSLV, Ms. Llorens Moltó, F. OFM. "Crónica del Convento de San Lorenzo (años 1909-1940). Primera parte y Segunda parte": 91-198, en DDAA. Datos para la Crónica del Convento-Residencia de San Lorenzo Mártir de Valencia, relata con todo lujo de detalles lo acontecido en esta etapa. Agulló, B. 2009: caps. IV-VI.

35 Como, en parte, realizó años atrás el arquitecto Josep Blesa i Morante y su equipo profesional multidisciplinar, del que el autor formó parte.
Agulló, B. OFM.; Prado, E. de. OFM. 2002. Fray Maseo Company Alfonso "arquitecto". Valencia.

Agulló, B. OFM. 2009. Convento de San Lorenzo, Franciscanos de Valencia. Valencia.

Benito Goerlich, D.; Serra Desfilis, A. 1995. El Palau de les Corts, antiga casa dels Borja. València: Consell Valencià de Cultura.

Bérchez, J. 1987. Los comienzos de la arquitectura académica en Valencia: Antonio Gilabert. Valencia: Federico Doménech Ed.

Burns, R. I. 1993. El regne croat de València. València: Tres i Quatre.

Cebrián i Molina, J. L. 1990. "La catedral de La Marina: una gran església neogòtica a Benissa", Actes del III Congrés d'Estudis de La Marina Alta: 367-379 Dénia: Institut d’Estudis Comarcals de La Matina Alta, Institut de Cultura Juan Gil-Albert, Escola-taller Castell de Dénia.

Cebrián i Molina, J. L. 2002. "L’església neogótica de Benissa". Festes Puríssima Xiqueta: sp.

Corbín Ferrer, J. L. 1988. Valencia histórica: entre El Salvador y Serranos. Valencia: Federico Doménech Ed.

Corell Vicent, J. 1997. Inscripcions romanes de Valentia i el seu territorio. València: Nau Llibres.

Corell Vicent, J. 2009. Inscripcions romanes de Valentia i el seu territori, amb la col-laboració de Xavier Gómez Font. València: Col·lecció Fonts Històriques Valencianes, Universitat de València.

DDAA. 1928. "Bodas de Oro de la restauración de la Seráfica Provincia de Valencia: 1878-1928". La Acción Antoniana, número extraordinario.

DDAA. 1995. Franciscanisme al País Valencià. València: Monogràfics. 22. Saó.

Gil Saura, Y. 2004. Arquitectura barroca en Castellón. Castellón: Diputación Provincial de Castellón.

Gavaldà, F. OP. 1979. Memoria de los sucesos particulares de Valencia, y su Reino en los años mil seiscientos quarenta y siete y quarenta y ocho, tiempo de peste. Valencia. Librerías París-Valencia. Edición facsímil de la edición de Valencia: Imp. de Joseph de Orga. 1804.

González Tornel, P. 2010. “José Mínguez. Un arquitecto barroco en la Valencia de la primera mitad del siglo XVIII". Goya 332: 212-227.

González Tornel, P. 2010. José Mínguez. Un arquitecto barroco en la Valencia del siglo xvill. Castellón: Col-lecció Humanitats, 35, Universitat Jaume $I$.

Igual Úbeda, A. 1953. Leonardo Julio Capuz (escultor valenciano del siglo XVIII). Valencia: Institución Alfonso el Magnánimo, Servicio de Estudios Artísticos.

Juan Vidal, F. 2000. Los campanarios de José Mínguez (Valencia 17001750). Valencia: Ediciones Generales de la Construcción.

López Azorín, M. J. 1993. "El testamento de Juan Pérez Castiel y otras noticias biográficas". Archivo de Arte Valenciano LXXIV: 75-80.

Llop i Bayo, F.; Martín Noguera, X. 1998. Metodologia dels inventaris de campanes.

Madoz, P. 1982. Diccionario geográfico-estadístico-histórico de Alicante, Castellón y Valencia. II. Valencia: Institución Alfonso el Magnánimo. Edición facsímil de la edición de Madrid: Tip. P. Madoz. 1845-1850.

Martínez Aloy, J. 1920-27. "Provincia de Valencia”, en Geografía general del Reino de Valencia, 2, en F. Carreras y Candi (dir.) Barcelona: Alberto Martín.

Orellana, M. A. de. 1980. Tratado histórico-apologético de las mugeres emparedadas. Valencia: Biblioteca Valenciana, Librerías ParísValencia. Edición facsímil de la edición de Valencia: Imp. de la Casa de Beneficencia. 1887.

Pingarrón, F. 1984. "La factoría de órganos Salanova-UsurraldeGrañena. 1719-1728-1738". Cabanilles 10-11 (monográficos).

Pingarrón, F. 1998. Arquitectura religiosa del siglo XVII en la ciudad de Valencia. Valencia: Col-lecció Estudis, 12, Ajuntament de València.

Teixidor, J. OP. 1985. Antigüedades de Valencia. I. Valencia: Biblioteca Valenciana, Librerías París-Valencia. Edición facsímil de la edición de Valencia: Imp. de Francisco Vives Mora. 1895. 


\section{APÉNDICE DOCUMENTAL}

\section{Documento no 1}

1662, marzo, 20, Valencia

Inventario de los ornamentos de la iglesia de San Lorenzo.

APPV, Protocolos de Cosme Puig, no 17.547.

"Anno a nat(ivitate) Domini MDCLXII die vero intitulato vigessimo mensis Martii, constituhits en la Yglesia de Sent Llorens Don Vicent Català y López, Don Melchor Figuerola, Señor de Nàquera, y Berthomeu Ros, elets de dita Parròquia per a efecte de proseguir lo inventari dels ornaments de dita Yglesia, los quals prosegueixen aquells en presència del Licençiado Bernardo Salafranca, Retor de dita Yglesia Parrochial, y de Mossén Joseph Climent, sacristà de dita Parrochia en la forma següent.

Primo en la sacristia de la Capella de la Mare de Déu fonch atrobat lo següent:

Primo un frontal de rasso blanch molt vell y romput en caygudes de tercipelo negre y mostres blanques y gotera de vert daurats y blanch.

Ittem altre frontal de terciopelo vert molt vell y gotera del mateix.

Ittem altre frontal morat de llana ab mostres ab la cayguda del mateix y enmig de dit frontal unes armes de les ànimes bordades.

Ittem altre frontal de brocadelo de groch y blanch en caygudes del mateix.

Ittem altre frontal de rasso vert en caygudes de brocadelo groch.

Ittem tretse blandons de festa plateats vells.

Ittem xexanta ramets de vert y plata ab dotse peus de fusta de carmesí y plata.

Ittem un drap de cordellat vert ab les armes de la Parrochia que servix per a el banch dels obrers ab franja verda.

Ittem lo pali de brocadelo de carmesí y groch en franja de carmesí y or.

Ittem huit vares de fusta daurades que servixen per al pali.

Ittem dos encendredors de fusta daurats.

Ittem una pinza de fusta daurada.

Ittem una caña en son ferro per a llevar los candeleros. Ittem en la sacristia de dita Yglesia fonch atrovat lo següent.

Primo en un almari se trova lo següent:

Primo un calis gran de plata sobre dorat gravat y en la patena ya un Christo ab la ymage de Sent Llorens, y Sent Gil.

Ittem dos calis y una patena, lo hu de plata sobre daurat y l'altre de plata.

Ittem una ymage de Nostra Señora de plata sobre daurada ab sa corona de plata y un Niño ab un món en la mà y sa crehueta.

Ittem una ymage de Sent Llorens de plata sobre dorada ab sa corona de plata, palma y graelles del mateix.

Ittem un Sent Gil de plata sobre dorada ab sa corona de plata y ab lo báculo de plata sens serveta, la qual diu mossén Joseph Climent que la té en casa y que no té mans.

Ittem una ymage de Senta Anna de plata ab la Mare de Déu y el Niño al bras, y sols el Niño té corona.
Ittem un reliquiari de fusta sobre daurat, ala una part està Senta Teresa ab reliquies y al l'altra part una porta de Agnus gran ab un Sent Joseph, la Mare de Déu y el Niño.

Ittem una caxeta de plata ab unes armes del Cardenal López que és un camp daurat y un llop negre ab quatre peuets, dins la qual se trovaren les relíquies següents:

Primo la relíquia de Sent Llorens, que és lo ballador de lanca guarnit de plata sobre daurada.

Ittem una relíquia de Senta Anna guarnida de plata sobre daurada.

Ittem una relíquia de Senta Margarita guarnida de plata sobre dorada.

Ittem una relíquia de Sent Llorens guarnida de plata sobre dorada ab un lletrero que diu "un os del cap de Sent Llorens".

Ittem dos relíquies, la huna de Sent Cosme y l'altra de Sent Damià, guarnides de plata sobre dorada ab uns lletreros que diuen la una "Sent Cosme" y en l'altra "Sent Damià". Ittem una relíquia de Sent Christòphol guarnida de plata ab un lletrero a cada cap que diu "Christòphol".

Ittem una relíquia guarnida de plata ab un lletrero que diu de "Sent Pere Màrtir".

Ittem una relíquia de Sent Llorens guarnida de plata sobre dorada ab un Iletrero que diu "dit de Sent Llorens".

Ittem una relíquia de Sent Blay de plata que diu de "Sent Blay".

Ittem un reliquiariet ab una relíquia ab un lletrero dins que diu de "Monte Calvari".

Ittem una relíquia que dihuen ser de la pedra del pesebre en què naixqué Nostre Señor guarnida de plata.

Ittem una relíquia que dihuen ser de la coluna en què açotaren a Nostre Señor guarnida de plata.

Ittem un reliquiariet de plata sobre dorat sens relíquia.

Les quals relíquies com se ha dit están en dita caixeta y cubertes en un tafatà carmesí.

Ittem una creu de plata sobre dorada trepada en la qual està el Lignum Crucis custodit sens peu, en la qual falta un troset de ram dels quatre que ya.

Ittem un tafatà de encarnadillo guarnit ab una puntilla de plata.

Ittem un frontalet de tati naquerat ab un galó de or.

Ittem un altre frontalet de tela de or en uns galons de seda y or.

Ittem un altre frontalet de terciopelo vert bordat de cordonet de or en unes pesetes de plata ab una trepanadura de blanh y or.

Ittem un altre frontalet de lana blanca y or ab una franjeta de carmesí y or.

Ittem un canonet de bronçe ab difiniçió daurada que servix per a la Vera Creu y per no haveri més que inventariar, los dits señors elets ab asistènçia del dit Retor, los quals ornaments, plata y relíquies se entregaren a mossén Joseph Climent, sacristà, lo qual com fos present se entrega d'ells y prometé restituir aquells. Ittem per ittem y en la mateixa conformitat que están inventariats, per lo qual obliga sos béns ya actius Valentie fa.

Testes Viçent Rodrígues, scrivent, y Joan de Baix, escolà, Val(enti)a hab(i)t(a)t(ores)." 


\section{Documento no 2}

\section{3, mayo, 9, Valencia}

Capitulaciones para la fabricación del órgano de la iglesia de San Lorenzo entre mosén Vicente Casaña y los organeros Martín de Usurralde i Matías Salanova.

APPV, Protocolos de Josep Portillo, núm. 4.491, ff. 87 o-90 vo.

"Se pone por esta carta como nosotros Martín de Usurralde, Mathías Salanova, fabricantes de órganos, vesinos de esta ciud(ad) de Valencia, los dos juntos, de mancomún a vez de uno y cada de nos por si y por el todo insolidum renunciavit como expresam(en)te renunciamos las leyes de duabus reis debendi la authentica presente (...) y el benefisio de la división y execución y demás dexa en esta comunidad y fianza: Dezimos que hemos de renovar y hazer el órgano de la Yglesia Parroquial del Invicto Mártir San Lorenzo de esta ciud(ad) en la forma siguiente.

Memoria y capitulación de la renovación del órgano de la Parroquial Yglesia del Glorioso Mártir San Lorenzo de la presente ciudad de Valencia.

Primeramente: se ha de hazer un secreto de madera vieja de pino de buena calidad con quareinta y siete canales con la profundidad necesaria para la música que abaxo se dirá partido a lo moderno con sus tapas y registros, tirantes de madera y todos los árboles de los registros se han de hazer de Lerro.

Otrosí: se ha de hazer un teclado de quarenta y siete teclas, las blancas de hueso y las negras rebutidas de olmo con sus tirantes (...).

Otrosí: se ha de hazer un fuelle nuevo correspondiente a los que (h)oy en día tiene el órgano que son tres los que se han de desazer y renovarles como si de nuevas se hisieran que hazer el número de quatro, y se han de colocar en alto si el sitio diese lugar con su conducto y palancas para el usso de ellas.

\section{Música}

Primeram(en)te: ha de aprovechar el flautado mayor de $\mathrm{d}(\mathrm{ic})$ ho órgano añadiéndole dos caños graves por baxo y tres tiples por arriba reconociéndole y reformando de voz en la mejor forma que sea dable.

Otrosí: Assimismo ha de aprovechar en el registro de el flautado bioton que (h)oy en día tiene dicho órgano añadiéndole en la misma forma que al flautado mayor los caños que le corresponden.

Otrosí: Se ha de hazer un registro en octava arriba del flautado, todo nuevo, de metal, caños quarenta y siete.

Otrosí: se ha de hazer un registro en quinsena todo nuevo de metal, caños quarenta y siete.

Otrosí: se ha de hazer un registro de clarón o toloima que todo es uno de tres caños por tecla de ambas manos se guiasen diez y novena caños ciento cuar(en)ta y una.

Otrosí: se ha de hazer un registro de lleno de quatro caños por tecla la guía en ventidozena con sus compuertas y reyteraciones según ante caños ciento ochenta y ocho.

Otrosí: se ha de hazer un registro de cimbal (...) caños por tecla la guía en veinte seis sería con sus (...) y reyteraciones lo mismo que el lleno de arriba disponiendo las reyteraciones en diferentes términos que el lleno de arriba caños ciento ochenta y ocho.

\section{Música moderna}

Primeram(en)te: se ha de hazer un registro de nasardo en doce a de ambas manos, todo nuevo de metal, caños cuarenta y siete.

Otrosí: se ha de hazer otro registro de nasardo en quincena de ambas manos, todo nuevo de metal, caños quarenta y siete.

Otrosí: se ha de hazer un registro de nasardo en diezisetana de ambas manos, todo nuevo y de metal caños quarenta y siete. Con la prevención que estos tres registros de nasardos han de llevar movimientos separados de ambas manos.

Otrosí: se ha de hazer un registro de corneta macna de siete caños por tecla partido de mano $d(e)$ recha con secreto y conductos aparte colocado en alto para su mayor desa(h) ogo, caños ciento sesenta y ocho.

Otrosí: se ha de hazer un registro de trompetas reales de ambas manos unisoni al flautado mayor con su secreto aparte colocadas a la parte de adentro y a la testa de el secreto para que con más facilidad se puedan afinar todo de metal caños quarenta y siete.

Otrosí: se ha de hazer un registro de trompeta macna partido de mano drecha colocado en la forma misma que la trompeta real caños veinte y quatro.

Otrosí: se ha de hazer un registro de baxo anillo partido de mano yzquierda puesto y colocado (...) del escrito por la parte de (...) forma de artillería, caños veinte y tres.

Otrosí: se ha de hazer en registro de clave claro partido de mano d(e)recha puesto y colocado de la misma forma que el bastonzillo, caños veinte y quatro.

Otrosí: se advierte que han de aprovechar las ocho contras de madera que tiene dicho órgano reformado de de vos haziéndole su secreto nuevo si fuere necesario con sus molinetes y pisantes andas a las teclas que le corresponden caños ocho.

\section{Cadireta}

Primeram(en)te: se ha de hazer un segundo secreto para dicha cadireta, con las mismas circunstancias que el secreto principal, y se ha de colocar de baxo del órgano mayor.

Otrosí: se ha de hazer un segundo teclado para dicha cadireta y con las mismas circunstancias que el de arriba.

\section{Música}

Primeram(en)te: se ha de hazer un registro de flautado violón de ambas manos los diez graves de madera y los restantes tre(i)nta y siete de metal, caños quarenta y siete.

Otrosí: se ha de hazer un registro en octava arriba de el violón de ambas manos, todo de metal, caños quarenta y siete.

Otrosí: se ha de hazer un registro de corneta eco partido de mano d(e)recha de cinco caños por tecla la guía y el flautado tapado con movimientos aparte, caños ciento y veinte.

Otrosí: se ha de hazer un registro de violines partido de mano derecha con las mesmas circunstancias que se presisan en los demás órganos, advirtiendo que la corneta de eco y el violín se han de colocar dentro de un taco para que haga eco y contraeco, y con su movimiento al pie para que 
el tañedor pueda usar de ella con mayor facilidad, caños veinte y quatro.

Dicha obra se dará escrita y reconocida por perjuicio de inteligencia y conciencia a satisfacción de el re(c)tor, de cuyo cargo y consentimiento se manda fabricar conviniendo en aquellos plazos y tiempo que el re(c)tor se sirva de disponer obligándonos de compañía los abaxo firmados, advirtiendo que dicho señor re(c)tor o Parroquia tenga obligación e darnos sitio capas para colocar toda la obra expresada en los capítulos antecedentes que dichos factores queden esemptos y libres de pagar ninguna obligación de escrituras, ni autos, que en semejante asumpto que ocasionan assimismo que haya de correr de quenta y corte d(ic)ho señor $\operatorname{Re}(c)$ tor o Parroquia como es a viento de secreto y de fuelles y si acaso se ofreciese algún remiendo en la caxa cosera preciso hazer una ventana (...) para el órgano principal y una puerta para la corneta. Esto se previene por ser cosa de carpintería y no de nuestra perícia y ser preciso.

Cuya fábrica la dexaremos perfectam(en)te concluyda sirviendo para nosotros el órgano viejo, excepto la caxa, dándonos a más de ello quinientas y cinquenta libras, moneda de este reyno en esta forma. Ciento y diez libras en el día de (h)oy, ciento y diez libras en el día y fiesta de San Juan de Junio (de) mil setecientos quarenta y quatro, ciento y diez libras en el día y fiesta de San Juan del año mil setecientos quarenta y cinco, ciento y diez libras en el día y fiesta de San Juan de Junio (de) mil setecientos quarenta y seis, y ciento y diez libras en el día y fiesta de San Juan de junio de mil setecientos quarenta y siete. Obligándose para ello el Dr. y Pavorde Vicente Casaña, cura actual de d(ic)ha Yglesia Parroquial de San Lorenzo.

Hallándome presente yo dicho Dr. Vicente Casaña me obligo de satisfacer y pagar de mis efectos proprios $\mathrm{d}$ (ic)has quinientas y cinquenta libras en la referida forma y plazos en atención a la inutilidad de d(ic)ho órgano que quasi no se puede tañer, y de fabricarse en la forma referida será más espléndido y decente el culto divino. Por tanto, y cumpliendo lo referido, me obligo de satisfacer y pagar a d(ic)hos Martín de Userralde y Mathías Salanova las expresadas quinientas y cinquenta libras, a saber: las ciento y diez libras de contado y las restantes en los d(ic)hos plazos a razón de ciento y diez libras cada uno, según queda estipulado llanam(en)te y sin pleyto alguno con las costas de la cobranza, cuya execución difiero en su juram(en)to y esta esc(ritur)a y les recievo de otra prueba. Y nosotros, dichos de Userralde y Salanova en conformidad de d(ic)ha, estipulación otorgamos y confesamos que recibimos de d(ic)ho Do(c)tor Vicente Casaña, real y efectivam(en)te, las dichas ciento y diez libras en presencia del infrascrito esc(riba)no y testigos y en moneda de oro, plata y vellón corriente de que se me pide dé fe; e yo la doy de haver pasado a poder de d(ic)hos fabricantes la expresada quantía en d(ic)ha España por lo que le otorgamos de d(ic) ho primer plazo carta de pago en forma, dexándole libre por razón de él de su obligación y subsistente esta escritura para las restantes quatrocientas y quarenta libras que hemos de cobrar en $\mathrm{d}(\mathrm{ic})$ hos plasos. $\mathrm{Y}$ ambas partes, cada una por lo que nos toca cumplir, obligamos y (...): Nosotros, d(ic)hos fabricantes, nuestras personas y bienes; e yo el d(ic)ho Dr. Vicente Casaña, mis bienes havidos y por haver. $Y$ damos poder, nosotros los expresados de Userralde y Salanova a los juezes y justicias de Su Mag(esta)d y, en especial, a los de esta d(ic)ha ciud(ad) a cuya jurisdicción nos sometemos e a nuestros bienes y renunciamos nuestro proprio fuero, jurisdicción y domicilio, y otro que de nuevo ganaremos y la ley si convenerit de juridictione omnum judicum y la última pragmática de las sumiciones y demás leyes e fueros de nuestro favor y la general del $d(e)$ recho en forma para que nos apremien como por sentencia pasada en cosa jusgada y por nosotros consentida. E yo d(ic)ho Do(c)tor Casaña doy poder a las justicias eclesiásticas de mi fuero para que me apremien como por sentencia pasada en cosa juzgada, por mi consentida y renuncio el capítulo suam deponi o duardus de solutionis de cuyo efecto soy sabidor y las demás leyes de mi favor y la general del d(e)recho en forma, en cuyo testimonio a mi te otorgamos en esta dicha ciud(ad) de Valencia, a los nueve días del mes de mayo de mil setecientos quarenta y tres años, siendo testigos $\mathrm{M}$ (osé)n Joseph Molmà y M(osé)n Juan B(a)u(tis)ta Fransa, P(res)b(íte)ros de esta $\mathrm{d}$ (ic)ha ciud(ad) vecinos. Y los tres otorgantes (...) Yo el esc(riba)no doy fe, conosco y lo firmaron.

Dr. Vicente Casaña, R(ector) y Pavorde

Martín de Ussarralde

Mathías Salanova

Ante mí

Joseph Portillo "

\section{Documento $n=3$}

1912-13, Valencia

Reparación de la cubierta de la iglesia de San Lorenzo por los franciscanos.

ACSLV, Papeles sueltos, "Iglesia de San Lorenzo. Su reparación", sf.

"Entregada á la Comunidad de esta ciudad de Valencia la actual iglesia de S. Lorenzo, mártir, por el Exmo. Y Rmo. Sor. Arzobispo de esta archidiócesis, Dr. D. Victoriano Guisasola para que trabajásemos con mayor ahínco y desembarazo en el provecho espiritual de los fieles, nos encargamos de la misma el día 31 de enero de 1908; y al día siguiente, 1으 de Febrero, se abrió al culto bajo la custodia y dirección de esta Comunidad.

Como hasta el año 1903 había sido iglesia parroquial, y desde esta fecha hasta que la Comunidad se encargó, venía siendo una filial de la de S. Bartolomé, apóstol, servida tan solo por un Vicario de esta parroquia, debido á los siglos transcurridos desde su erección y al continuo uso de la misma, la encontramos bastante deteriorada y estropeadísimo su pavimento, exceptuando tan solo el altar mayor y la techumbre de la nace central, que hacía pocos años habían sido decorado aquel y renovada ésta.

Posesionada la Comunidad de dicha iglesia, se aumentó el culto en la misma, estableciendo un grande y continuo servicio espiritual en bién de los fieles. Los cuales principiaron á acudir en mayor número día a día, y por lo mismo á ser la iglesia más castigada en las idas y venidas de las multitudes que en ella se congregaban. Lo cierto es, que hacía algunos meses principiaron á aparecer grietas en las bóvedas de la nave central de la misma: grietas que algunas de ellas habían alcanzado tales dimensiones el verano pasado, que hacían concebir verdaderos temores de algún desprendimiento por lo menos.

En vista de esto, el V(enera)ble Directorio de este Convento en la reunión habida el día 2 de Julio de 1912 
determinó, según reza el libro de Actas, en la 2ª parte de la vigésima que: “Vista la necesidad urgente que tenían de una pronta reparación las bóvedas de la iglesia por su ruinoso estado, y contando con una buena limosna que se había dado para este fin, se procediese á las obras de reparación de aquellas y al decorado de la misma iglesia y renovación del piso".

Una vez determinadas y aprobadas por el V(enera)ble Directorio las obras de reparación de esta iglesia, el R. P. Guardián comunicó este proyecto al M. R. P. Provincial; el cual asintió á él, no sin manifestar que antes debía revisarse é inspeccionarse la iglesia por un arquitecto de Valencia para que emitiese su dictamen respecto al estado ruinoso en que la misma se encontrase, para precisar las reparaciones que fueran necesario hacerse; á fin de proceder debidamente y evitar gastos que fueran inútiles; así como también para eximir a la Comunidad de las responsabilidades que prescriben las leyes, en el caso de ocurrir alguna inesperada desgracia durante la realización de las obras.

Al efecto se le suplicó al señor arquitecto, don Antonio Martorell, que se dignase revisar la iglesia para informar á la Comunidad del estado en que se encontraba, el cual se personó en ésta el 26 de Julio último, y habiendo inspeccionado las bóvedas de la nave central en su cara externa é interna, emitió su dictamen en presencia del R. P. Guardián, del P. Justino y de Fr. Maseo. Comunicado ese dictamen al V(enera)ble. Directorio, se reunió en sesión al siguiente día y determinó de conformidad y aprobación del Síndico de la Comunidad lo que se consigna en el Acta 22a que literalmente copiada, dice: "Reunidos los P. P. Discretos de este convento de S. Lorenzo, mártir, presididos por el R. P. Guardián del mismo, el día y mes de la fecha previa la invocación del Espíritu Santo y tratado maduramente el asunto de las obras de reparación y decorado de la iglesia, afirman: Que inspeccionadas detalladamente las bóvedas de la misma con sus respectivos arcos, el día 26 del actual, por el sor. arquitecto D. Antonio Martorell, cuyo resultado fue: 'Que no ofrecían peligro inminente, a pesar de la desviación sufrida por todas ellas; y que para mayor seguridad é instabilidad de las mismas, bastaba tan solo una buena reparación de todas las bóvedas, excepción hecha de la del presbiterio, que era conveniente hacerse nueva.'

Propuestas estas reparaciones al maestro de obras D. Rafael Sancho, lo mismo que los trabajos del estucado de la iglesia, contrató el Síndico de la Comunidad ante el unánime consentimiento del R. P. Guardián y V(enera)ble Directorio, cederle á dicho señor todas estas obras con los gastos del andamiaje, asentar los zócalos de la iglesia y dejar preparado el lecho de la misma para la colocación del piso, por la cantidad de nueve mil pesetas; desentendiéndose la
Comunidad de todas las consecuencias que pudieran sobrevenir durante dichas obras, y habiendo de quedar ultimadas éstas el día 30 del próximo setiembre.

En fé de lo cual lo firman el Síndico con el V(enera)ble Directorio en éste de Valencia á 27 de Julio 1912.

Fr. Fernando Fabregat, Guardián

Fr. Vicente Corell, Dir(ec)t(ori)o

Fr. Estanislao Domínguez, Dir(ec)t(ori)o

Fr. Justino M. Candela, Dir(ec)t(ori)o

Enrique Pérez, Síndico

Perfectamente enterado Fr. Maseo del dictamen del sobredicho sr. arquitecto y de la resolución tomada por el V(enera)ble Directorio, el R. P. Guardián le puso al frente (al indicado Religioso) de las obras para que se encargase de hacer que se reforzasen y consolidasen debidamente las bóvedas centrales de la iglesia y que se renovase la del presbiterio; procediéndose á la vez al decorado y asentamiento del nuevo piso de la iglesia.

Realizadas felizmente las obras, para los efectos oportunos, se consigna á continuación una detallada relación de los gastos que han ocasionado, con los recibos justificantes de los mismos al final de esta memoria; lo mismo que las limosnas recibidas para llevar á cabo tales obras (...)."

\section{Documento $n \cong 4$}

1916, abril, 10, Valencia

Intervención en las fachadas de la iglesia de San Lorenzo por el arquitecto Javier Goerlich Lleó.

AHMV, Fomento, Policía Urbana, 1916.

"Exmo. Sr.

El arquitecto que suscribe á Vd. atentamente EXPONE:

Que con el fin de mejorar el aspecto actual de las fachadas de la Iglesia de San Lorenzo me ha sido encargado por el Padre Fr. Lorenzo Pérez, Rector de dicha iglesia, la construcción de los antepechos de coronación correspondientes a las fachadas de la calle y plaza de San Lorenzo como igualmente una pequeña torre cuyo vuelo será de 30 centímetros como composición ornamental del remate de ambas fachadas. Al mismo tiempo se procederá también al revoco y pintado total de las mencionadas fachadas.

Por lo expuesto;

SUPLICA á V. E. que previos los trámites reglamentarios, se digne conceder la licencia que se solicita.

Valencia 10 Abril de 1916.

Fr. Lorenzo Pérez

Javier Goerlich

Sr. Alcalde Presidente del Exmo. Ayuntamiento de esta Ciudad." 